\title{
Lansky Performance Status 30
}

National Cancer Institute

\section{Source}

National Cancer Institute. Lansky Performance Status 30. NCI Thesaurus. Code C70541.

In bed; needs assistance even for quiet play. 